\title{
Ontogeny and nutritional manipulation of mitochondrial protein abundance in adipose tissue and the lungs of postnatal sheep
}

\author{
A. Mostyn ${ }^{1}$, V. Wilson ${ }^{1}$, J. Dandrea ${ }^{1}$, D. P. Yakubu ${ }^{1}$, H. Budge ${ }^{1}$, M. C. Alves-Guerra ${ }^{2}$, \\ C. Pecqueur ${ }^{2}$, B. Miroux ${ }^{2}$, M. E. Symonds ${ }^{1 *}$ and T. Stephenson ${ }^{1}$ \\ ${ }^{1}$ Academic Division of Child Health, School of Human Development, Queen's Medical Centre, \\ University Hospital, Nottingham NG7 2UH, UK \\ ${ }^{2}$ CNRS-CEREMOD, 9 rue Jules Hetzel, 92190 Meudon, France
}

(Received 9 January 2003 - Revised 21 March 2003 - Accepted 12 April 2003)

\begin{abstract}
The present study examined the ontogeny of mitochondrial protein abundance in adipose tissue and lungs over the first month of life in the sheep and the extent to which this may be altered by maternal undernutrition during the final month of gestation. The ontogeny of uncoupling protein (UCP), voltage-dependent anion channel (VDAC) and cytochrome $c$ abundance were determined in adipose tissue and lungs sampled from near-term fetuses and young sheep aged $4 \mathrm{~h}, 1,7$ and $30 \mathrm{~d}$. In adipose tissue, the abundance of UCP1, VDAC and cytochrome $c$ all peaked at $1 \mathrm{~d}$ of age and then decreased by $30 \mathrm{~d}$ of age, at which stage the brown adipose tissue-specific UCP1 was no longer detectable but UCP2 was clearly abundant. For the lungs, however, UCP2 and VDAC abundance both peaked $7 \mathrm{~d}$ after birth and then decreased by $30 \mathrm{~d}$ of age. During postnatal development, therefore, a marked change in mitochondrial protein abundance occurs within both adipose tissue and lungs. Maternal nutrient restriction had no effect on lamb growth or tissue weights at $30 \mathrm{~d}$ of age but was associated with increased abundance of UCP2 and VDAC but not cytochrome $c$ in both adipose tissue and lungs. These mitochondrial adaptations within both adipose tissue and the lungs of offspring born to previously nutrient-restricted mothers may compromise adipose tissue and lung function during periods of environmental stress.
\end{abstract}

Adipose tissue: Development: Lungs mitochondria: Proteins

Adaptation to cold exposure of the extra-uterine environment is an important stimulus for the onset of both independent breathing and thermoregulation (Symonds et al. 1995). As a consequence the newborn has a rapid rate of breathing and a high metabolic rate (Andrews et al. 1989b). A critical response at birth is therefore the initiation of non-shivering thermogenesis through the rapid appearance and activation of the brown adipose tissue-specific uncoupling protein (UCP)1 (Clarke et al. 1997). This is important in preventing hypothermia and maintaining a high rate of respiration. Other UCP have now been identified which are members of the subfamily of inner mitochondrial membrane carriers (Fleury et al. 1997; Gong et al. 1997; Ricquier \& Bouillaud, 2000). These include UCP2 which is highly abundant in the lung (Pecqueur et al. 2001). The function of UCP2 remains a subject of intense debate (Stuart et al. 2001) and it may have a role in energy balance (Buemann et al. 2001), reactive oxygen species production (Negre-Salvayre et al. 1997) and apoptosis (Voehringer et al. 2000). It is established that UCP1 abundance peaks very soon after birth and then is gradually lost and in sheep is no longer detectable by 1 month of age. The extent to which the ontogeny of UCP2 in the lung may show a parallel ontogeny to that for UCP1 has not been established. It is also unknown whether there is a parallel loss of other mitochondrial proteins in addition to UCP1 as adipose tissue function adapts from one of heat production to energy storage.

An important factor determining metabolic adaptation at birth is the maternal nutritional and endocrine environment (Symonds et al. 1995). Fetal or neonatal sheep of nutrientrestricted mothers can have depleted adipose tissue stores and show compromised lung development. Importantly a $50-60 \%$ reduction in maternal food intake over the final month of gestation does not have any inhibitory effect on birth weight, despite a significant reduction in fetal plasma glucose and insulin concentrations (Edwards et al. 2001; Yuen et al. 2002). Despite these fetal adaptations to maternal undernutrition there appears to be no negative effect on mitochondrial protein abundance. Neonatal sheep that were nutrient-restricted over the final month of gestation show a marked up regulation of specific mitochondrial proteins within adipose tissue (Budge et al. 2003). These include UCP1, voltage-dependent anion 
channel (VDAC) and cytochrome $c$ which are all important in the control of energy metabolism within the adipocyte. The extent to which mitochondrial function in either adipose tissue or the lung remains altered following maternal undernutrition remains poorly understood. The present study aimed to determine whether the ontogeny of UCP, VDAC and cytochrome $c$ was similar between adipose tissue and the lung over the first month of life. At the same time, the hypothesis was examined that maternal nutrient restriction over the final month of gestation results in a persistent up regulation of mitochondrial proteins within these tissues.

\section{Methods \\ Ontogeny of adipose tissue and lung mitochondrial development}

Perirenal adipose tissue (which constitutes about $80 \%$ of adipose tissue in a newborn lamb) and lungs were sampled from near-term fetuses ( $145 \mathrm{~d}$ gestation, $n$ 4) and lambs born normally at term ( $148 \mathrm{~d}$ gestation, $n$ 20) to Border Leicester cross Swaledale ewes. The lambs were sampled at either $4 \mathrm{~h}, 1,7$ or $30 \mathrm{~d}$ after birth (n 5 per sampling age) following euthanasia with an overdose of the barbiturate pentobarbital sodium $(200 \mathrm{mg} / \mathrm{kg}$, Euthatal; RMB Animal Health, Stoke, Staffordshire, UK). The tissues were rapidly dissected, weighed and then placed in liquid $\mathrm{N}_{2}$ and stored at $-80^{\circ} \mathrm{C}$ until analysed. All ewes were fed $100 \%$ of their total metabolisable energy requirements (taking into account requirements for both ewe maintenance and growth of the conceptus in order to produce a $4.5 \mathrm{~kg}$ lamb at term; Agricultural Research Council, 1980).

\section{Maternal nutritional manipulation of adipose tissue development}

Fourteen 2-year-old primiparous Border Leicester cross Swaledale ewes of similar weight and condition score and confirmed as bearing twins were entered into the study. Of the ewes, six were fed and consumed $100 \%$ of total metabolisable energy requirements at each stage of gestation (see earlier) to serve as controls whilst the remaining eight ewes were nutrient-restricted and consumed $60 \%$ of total metabolisable energy requirements for the final month of gestation. The diet comprised chopped hay and concentrate and was provided in a 3:1 weight ratio for which the composition of the concentrate was (g/kg): barley, 707; soya, 200; molassed meal, 50; minerals, 25; limestone, 25; phosphate, 7; calcium magnesate, $2 \cdot 5$; vitamin E, $0 \cdot 3$. The gross composition of the hay and concentrate are given in Table 1. All animals had continual access to a mineral lick.

All ewes lambed normally at term and each ewe then reared a single lamb until it was $30 \mathrm{~d}$ old when it was tissue sampled as described earlier. The other twin was euthanased within $6 \mathrm{~h}$ of birth. Throughout lactation ewes were fed hay ad libitum and up to $1 \mathrm{~kg}$ concentrate. All operative procedures and experimental protocols had the required Home Office approval as designated by the Animals (Scientific Procedures) Act (1986).
Table 1. Composition of concentrate and chopped hay $(\mathrm{g} / \mathrm{kg})$

\begin{tabular}{lcc}
\hline & Concentrate & Chopped hay \\
\hline DM & 857 & 849 \\
Total crude protein & 229 & 90 \\
Crude fibre & 60 & 374 \\
Digestibility (\%) & 85.5 & $59 \cdot 0$ \\
Metabolisable energy (MJ/kg DM) & $12 \cdot 7$ & $9 \cdot 1$ \\
Ash & 70 & 69 \\
\hline
\end{tabular}

\section{Laboratory procedures}

Mitochondria were prepared from each tissue as described by Symonds et al. (1992) and protein content determined by the method of Lowry et al. (1951). Abundance of cytochrome $c$ was determined on $10 \mu \mathrm{g}$ mitochondrial protein using an antibody ('Santa Cruz', Santa Cruz, CA, USA) at a dilution of 1 in a 1000 . VDAC abundance was determined using an ovine-specific antibody prepared 'in house' and used at a dilution of 1 in 2000. VDAC peptide was purified from the kidney of a newborn lamb based on the method of Schermer et al. (1996) as described for UCP1 and subjected to hydroxyapatite chromatography. Rabbits were then immunised with the resulting VDAC protein $(100 \mu \mathrm{g}$ was used for the initial immunisation followed by three booster immunisations of $75 \mu \mathrm{g}$ ) and anti-sera samples were collected after 9 months. UCP1 content in brown adipose tissue was measured as described by Schermer et al. (1996). Abundance of UCP2 was determined using the same antibody as described by Pecqueur et al. (2001) at a dilution of 1 in 10000 , which was raised against human UCP2. A single band was detected at the same molecular weight as the UCP2 peptide in postnatal adipose tissue and lung samples (Fig. 1).

In order to confirm that the band detected in ovine samples with the UCP2 antibody was UCP2, representative samples were run on the same gel together with mitochondria prepared from brown adipose tissue sampled from wild-type and UCP2 knockout mice, produced as described by Pecqueur et al. (2001). Under these conditions, a band with an identical molecular weight to UCP2 was detected in all samples, except that which had been prepared from the brown adipose tissue of UCP2 knockout mice. The antibody raised against UCP2 cross-reacts with UCP1 so it was not possible to determine the abundance of UCP2 in mitochondria that possessed UCP1. Specificity of detection was confirmed using non-immune rabbit serum. A range of molecular-weight markers was included on all gels. Densitometric analysis was performed on each

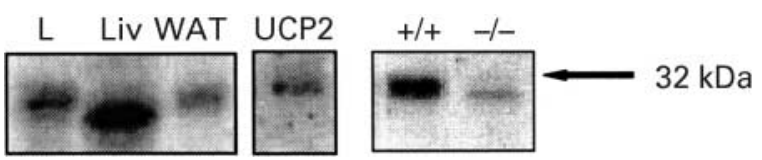

Fig. 1. Representative CCD-camera image of uncoupling protein (UCP)2 in mitochondria prepared from lung (L) and white adipose tissue (WAT) sampled from 30-d-old sheep and brown adipose tissue from UCP2 wild type $(+/+)$ and knockout $(-/-)$ mice. The protein detected for liver (Liv) is not at the correct molecular weight and is therefore not UCP2. 
membrane following image detection using a Fujifilm LAS-1000 cooled CCD camera (Fuji Photo Film Co. Ltd, Tokyo, Japan) and results expressed in densitometric units. All gels were run in duplicate and a reference sample (an appropriate ovine mitochondrial sample) was included on each to allow comparison between gels.

\section{Statistical analysis}

All data are presented as mean values with their standard errors. Statistical analysis with respect to significant differences $(P<0.05)$ between values obtained from the different ages of sheep or between control and nutrient-restricted groups was carried out using the Mann-Whitney U test.

\section{Results}

Ontogeny of mitochondrial proteins in adipose tissue and lungs

Both VDAC and cytochrome $c$ were detected in all adipose tissue samples and their relative abundance per $\mathrm{mg}$ mitochondrial protein peaked at $1 \mathrm{~d}$ of postnatal age (Figs. 2 (A) and $(\mathrm{B}))$ before declining significantly $(P<0.01)$ by $7 \mathrm{~d}$ of age, an adaptation continuing up to $30 \mathrm{~d}$ of postnatal age. Similarly, UCP1 abundance rose $(P<0.05)$ between $145 \mathrm{~d}$ gestation and $1 \mathrm{~d}$ after birth. It was no longer detectable at $30 \mathrm{~d}$ of age (Fig. 2 (C)) when UCP2 was clearly abundant, having an identical molecular weight to UCP2 run on the same gel (Fig. 1).

In lung mitochondria both VDAC and cytochrome $c$ were detected at all sampling ages. The abundance of cytochrome $c$ remained unchanged with age, whereas there was a significant $(P<0.05)$ decrease in the abundance of VDAC between $145 \mathrm{~d}$ gestation and $1 \mathrm{~d}$ after birth (Fig. 3). A further increase $(P<0 \cdot 05)$ followed at $7 \mathrm{~d}$ with a decrease at $30 \mathrm{~d}$ of postnatal age. In contrast, UCP2 was only detectable in postnatal lung mitochondria in which there was a distinct peak $(P<0 \cdot 01)$ in abundance at $7 \mathrm{~d}$.

\section{Effect of maternal nutrition on mitochondrial protein abundance in adipose tissue}

There was no difference between groups in lamb body or organ weights at birth or at 1 month of age (Table 2). Both adipose tissue and lungs of lambs born to nutrientrestricted ewes had a higher abundance of VDAC and UCP2 (Fig. 4) but not cytochrome $c$ (results not shown).

\section{Discussion}

The present study has demonstrated that there is a marked divergence in ontogeny of mitochondrial protein abundance between adipose tissue and the lung. In addition, it has been shown that the abundance of specific mitochondrial proteins involved in cellular metabolism are up regulated for at least the first $30 \mathrm{~d}$ after birth, following maternal nutrient restriction in late gestation. For adipose tissue, as established for UCP1, both VDAC and cytochrome $c$ were highly abundant on the first day
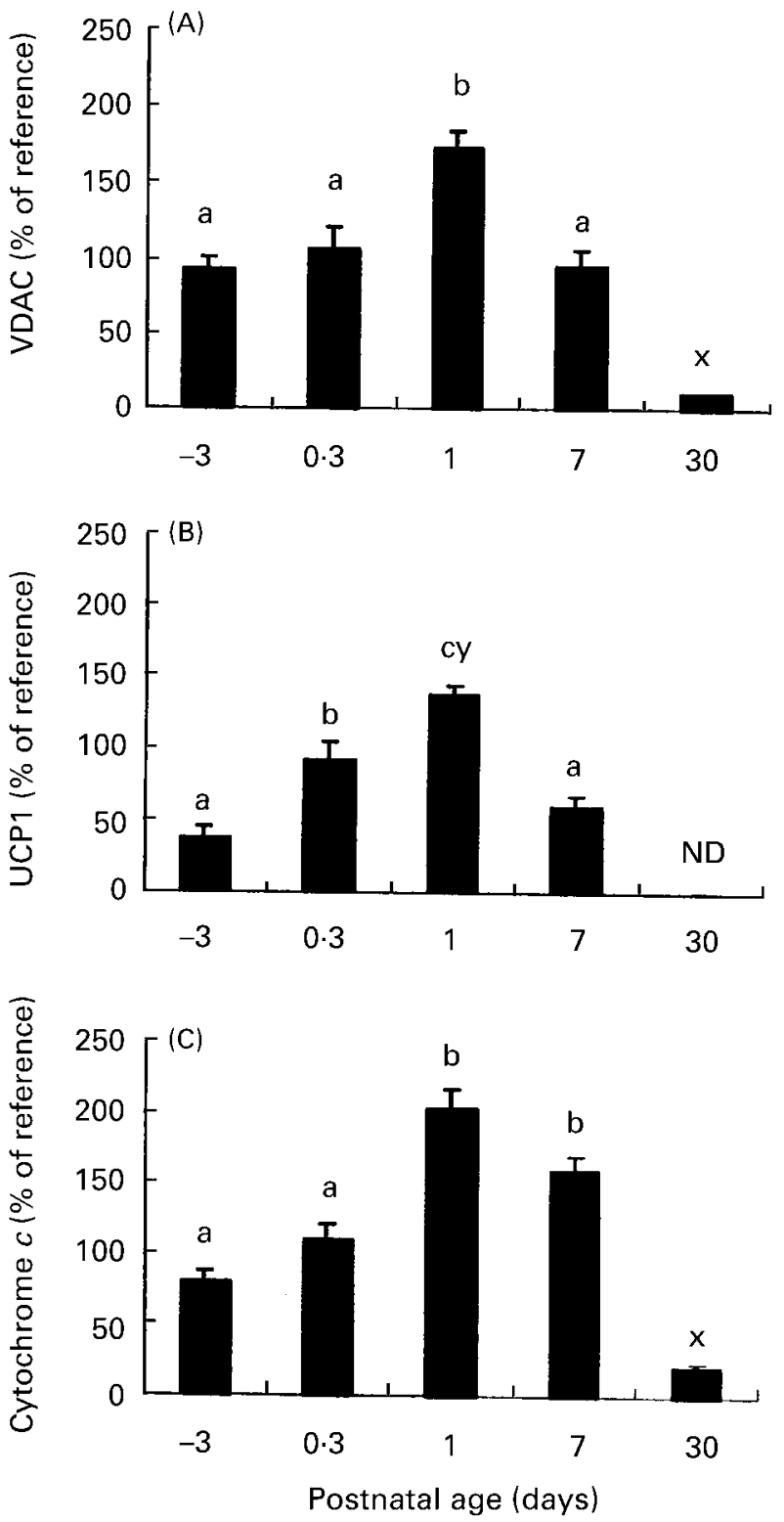

Fig. 2. Ontogeny of (A) voltage-dependent anion channel (VDAC) (B) uncoupling protein (UCP) 1 and (C) cytochrome $c$ in perirenal adipose tissue between late gestation (144 d gestation, $-3 \mathrm{~d}$ before birth) and 1 month of age in the sheep. ND, not detectable. Values are means with their standard errors ( $n$ 4-5 per time point). $a, b, c, x, y$ Mean values with unlike superscript letters were significantly different: $\mathrm{a} v$. $\mathrm{b}$ and $\mathrm{b} v$. $\mathrm{c}(P<0.05)$; $\mathrm{a} v$. $\mathrm{x}$ and $\mathrm{a} v$. $\mathrm{y}(P<0.01)$.

of birth and their subsequent decrease with postnatal age was closely correlated with the loss of UCP1. VDAC and cytochrome $c$ were still, however, present in white adipose tissue when UCP2 was also detectable (i.e. $30 \mathrm{~d}$ of age), confirming that each protein is present in white as well as brown adipose tissue. In the lung, although VDAC was present at a high concentration in the fetal lung, UCP2 was not detected until after birth and its abundance peaked at $7 \mathrm{~d}$ of age, coincident with a rise in VDAC but not cytochrome $c$. The abundance of each mitochondrial protein then decreased between 7 and $30 \mathrm{~d}$ of age. Importantly, this adaptive loss of mitochondrial proteins 

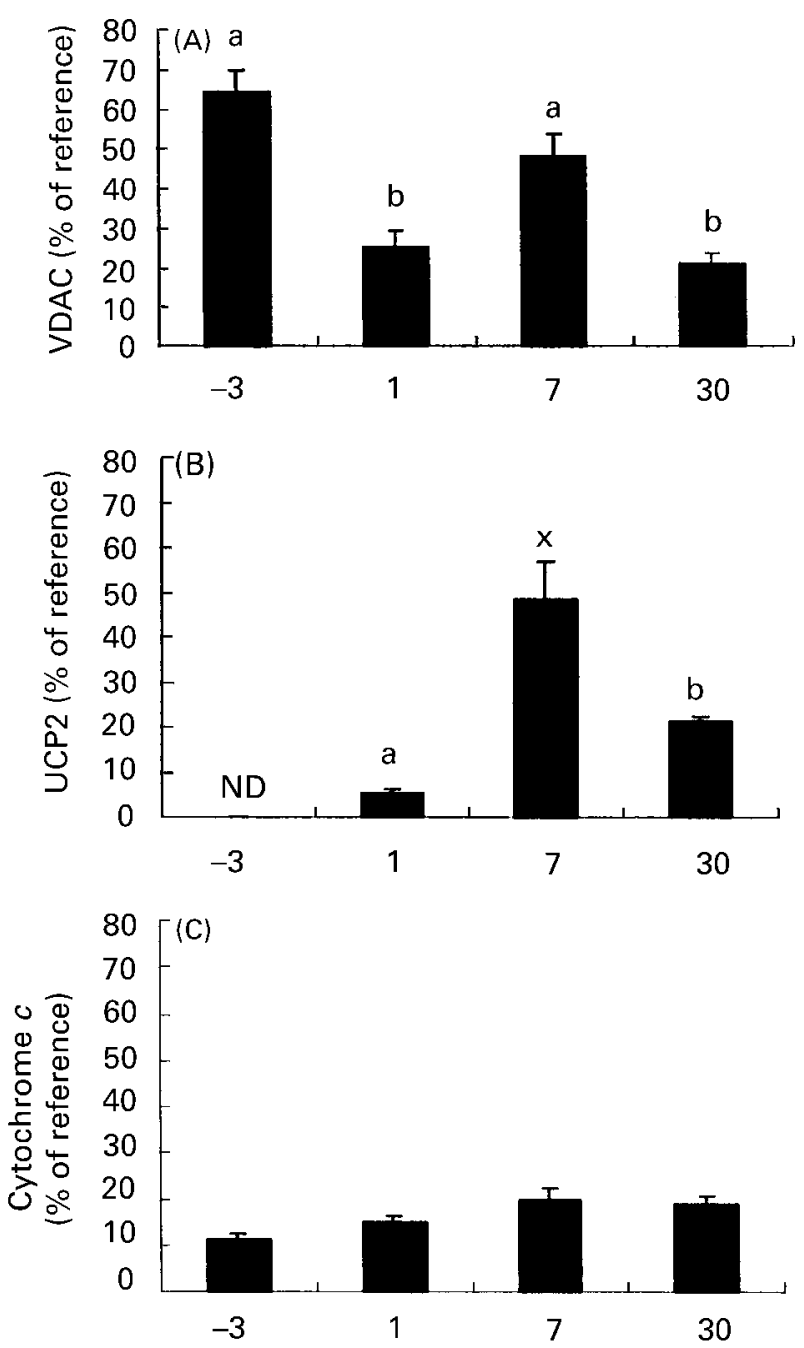

Fig. 3. Ontogeny of (A) voltage-dependent anion channel (VDAC), (B) uncoupling protein (UCP)2 and (C) cytochrome $c$ in lungs between late gestation (144d gestation, $-3 \mathrm{~d}$ before birth) and 1 month of age in the sheep. ND, not detectable. Values are means with their standard errors ( $n$ 4-5 per time point). ${ }^{a, b, x}$ Mean values with unlike superscript letters were significantly different: a $v$. b $(P<0.05)$; a $v . x$ and b $v . x(P<0.01)$.

in both lungs and adipose tissue at $30 \mathrm{~d}$ was markedly delayed in lambs born to ewes that were nutrient-restricted over the final month of gestation despite no differences in tissue, organ or body weights.
Maternal nutrition and the programming of adipose tissue and lung development

The increased abundance of both UCP2 and VDAC in adipose tissue mitochondria at 1 month of age of lambs born to nutrient-restricted ewes extends previous measurements made in adipose tissue soon after birth (Budge et al. 2003). This adaptation does not appear to be tissue-specific but includes the lungs. A greater abundance of mitochondrial proteins at birth within the primary tissues involved in metabolic adaptation to the extra-uterine environment can be interpreted as a beneficial response in order to prevent hypothermia. It may, however, have deleterious consequences in terms of adipose tissue deposition and lung function as metabolic rate continues to decline up to 2 months of age (Symonds et al. 1989). The exact mechanisms mediating these responses within the fetus clearly warrant further investigation. Restricted maternal nutrition during pregnancy normally results in a reduction in plasma concentrations of a range of anabolic hormones including insulin, insulin-like growth factors and thyroid hormones (Bauer et al. 1995; Clarke et al. 1998) which can all regulate adipose tissue development (Symonds et al. 1995). It also results in a short-term rise in maternal, but not fetal, plasma cortisol (Edwards \& McMillen, 2001). The extent to which endocrine adaptations of this type may directly impact on mitochondrial development within the fetus has not yet been determined. It is established that an intact fetal adrenal gland is critical for the maturation of both the fetal lungs (Fowden et al. 1998) and fetal brown adipose tissue (Mostyn et al. 2003), but this role does not appear to include the prepartum rise in either VDAC or cytochrome $c$ within adipose tissue.

In the present study, maternal food intake was reduced to $60 \%$ of total metabolisable energy requirements calculated to produce a $4.5 \mathrm{~kg}$ lamb (Agricultural Research Council, 1980). The lack of any inhibitory effect on birth weight is in accord with other studies using a comparable magnitude of nutrient restriction (Edwards et al. 2001; Yuen et al. 2002). This is despite a consistent reduction in fetal plasma glucose and a concomitant resetting of the sensitivity of the fetal hypothalamic-pituitary axis to hypoglycaemia (Edwards et al. 2001). Compensatory responses to maternal, and fetal, undernutrition are therefore occurring to maintain fetal growth. One consequence of these adaptations is an up regulation of mitochondrial protein abundance, which is dissociated from any effects on tissue growth. A higher abundance of UCP2 may have adverse

Table 2. Total body, perirenal adipose tissue and lung weights of sheep at birth and $30 \mathrm{~d}$ of age (Mean values with their standard errors)

\begin{tabular}{|c|c|c|c|c|c|c|c|c|}
\hline \multirow{3}{*}{$\begin{array}{l}\text { Group... } \\
\text { Age (d)... }\end{array}$} & \multicolumn{4}{|c|}{ Control } & \multicolumn{4}{|c|}{ Nutrient-restricted } \\
\hline & \multicolumn{2}{|c|}{0} & \multicolumn{2}{|c|}{30} & \multicolumn{2}{|c|}{0} & \multicolumn{2}{|c|}{30} \\
\hline & Mean & SE & Mean & SE & Mean & SE & Mean & SE \\
\hline Body (kg) & 4.05 & 0.25 & $15 \cdot 75$ & $1 \cdot 21$ & 3.60 & 0.25 & 14.50 & 1.40 \\
\hline Adipose tissue (g) & $17 \cdot 9$ & 1.7 & $151 \cdot 3$ & $15 \cdot 4$ & $19 \cdot 9$ & 1.5 & $165 \cdot 4$ & 11.4 \\
\hline Lungs (g) & $79 \cdot 7$ & $10 \cdot 0$ & $191 \cdot 2$ & 25.4 & 68.5 & 4.5 & $169 \cdot 7$ & $22 \cdot 1$ \\
\hline
\end{tabular}



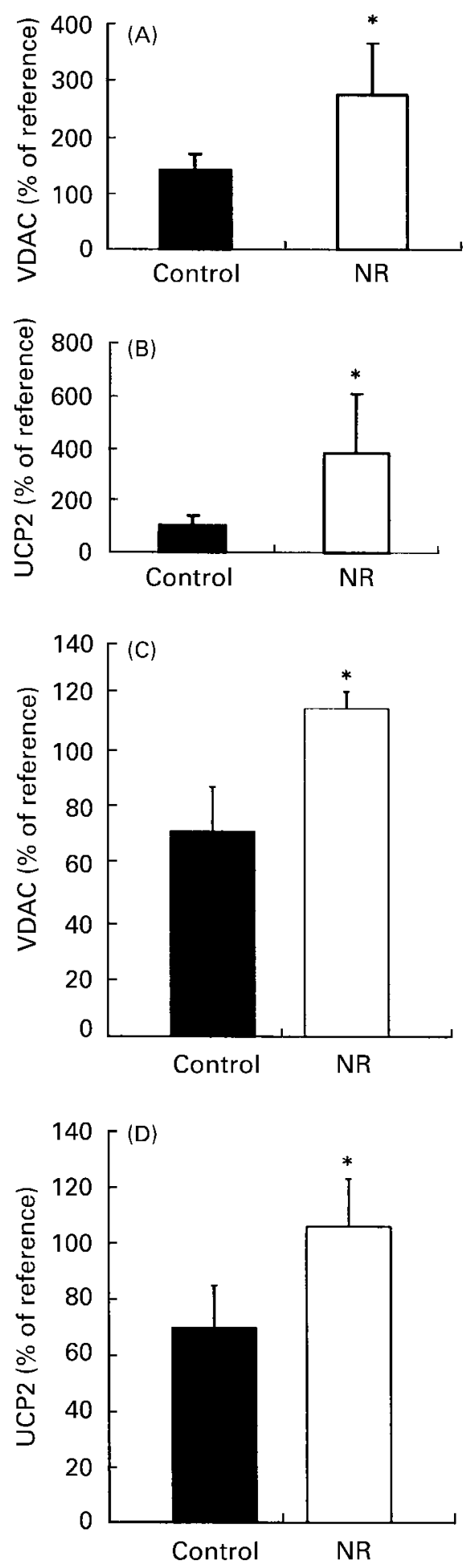

Fig. 4. Effect of maternal nutrient restriction over the final month of gestation on the abundance of voltage-dependent anion channel (VDAC; $A$ and $C$ ), and uncoupling protein (UCP)2 (B and D) in perirenal adipose tissue $(A$ and $B)$ and lungs $(C$ and $D)$ sampled from 1-month-old sheep born to mothers that consumed 60 (nutrient-restricted; NR) or $100 \%$ (control) of metabolisable energy requirements for maternal metabolism and fetal growth over the final month of gestation. Values are means with their standard errors ( $n$ 6-8 per group). *Mean value was significantly different from that for the control group $(P<0.05)$. consequences as this can result in enhanced susceptibility to infection and death from toxoplasmosis (Arsenijevic et al. 2000). It has also been shown that in obese women UCP2 gene exon 8 may affect susceptibility to obesity through an interaction with leptin (Cassell et al. 1999). Enhanced abundance of both UCP2 and VDAC could result in an accelerated rate of apoptosis (Voehringer et al. 2000).

It remains to be examined whether the adaptations that have been observed at $30 \mathrm{~d}$ of age are transient or persist into later life. Epidemiological studies have indicated that a similar magnitude of maternal nutrient restriction as adopted in the present study can predispose the resulting offspring to obesity or chronic lung disease in adulthood (Barker et al. 1991; Roseboom et al. 2000). These longterm consequences appear to be related to maternal undernutrition rather than intra-uterine growth retardation although it remains to be established if these long-term adaptations are linked.

\section{Postnatal development of adipose tissue and the lung}

The peak in abundance of both VDAC and UCP2 within the lung at $7 \mathrm{~d}$ of age are coincident with the time at which the metabolic stimulus to breathing begins to decline (Andrews et al. 1989b). This is associated with a decrease in breathing frequency and a concomitant rise in the recruitment of laryngeal braking, the function of which is to extend expiratory time, thereby increasing the time for gaseous exchange within the lung (Andrews et al. $1989 a$ ). It has been established that recruitment of this mechanism is markedly reduced in lambs born to nutrient-restricted ewes (Symonds et al. 1993). A change in breathing pattern may be related to the greater abundance of mitochondrial proteins, particularly UCP2, within lungs that could contribute to an adverse abundance of reactive oxygen species (Arsenijevic et al. 2000).

The function of VDAC has been most extensively studied in muscle for which deletion of the VDAC gene in mice indicates it has a role in ADP transport. Loss of the VDAC gene has tissue-specific effects resulting in greater mitochondrial sensitivity to ADP in the heart and gastrocnemius compared with decreased sensitivity within the soleus (Anflous et al. 2001). VDAC may have a significant influence on the supply of ADP in brown adipose tissue although this has yet to be confirmed. The parallel decline in UCP1, VDAC and cytochrome $c$ with increasing postnatal age was not unexpected as whole-body metabolic rate similarly declines over this period and shivering in skeletal muscle rather than non-shivering thermogenesis in brown adipose tissue becomes the dominant response to cold exposure (Symonds et al. 1989).

In conclusion, the similar ontogeny for UCP1, VDAC and cytochrome $c$ suggests that these mitochondrial proteins may all be important in ensuring brown adipose tissue maintains a maximal rate of thermogenesis at the critical time after birth. Parallel changes in these mitochondrial proteins are coincident with the transition of brown to white adipose tissue. In the lung UCP2 and VDAC abundance peak 1 week after birth and then decline up to 1 month of age. Critically the rate of change in VDAC 
and UCP2 within both these tissues can be significantly altered by maternal undernutrition in late gestation.

\section{Acknowledgements}

This work was funded in part by the Nottingham University Hospitals Research and Development Directorate. A. M. was funded by a University of Nottingham Postgraduate Scholarship and D. P. Y. by a University of Nottingham International Office Scholarship.

\section{References}

Agricultural Research Council (1980) Requirements for energy. In The Nutritional Requirements of Ruminant Livestock, pp. 115-119. Slough, UK: Commonwealth Agricultural Bureau.

Andrews DC, Symonds ME \& Johnson PJ (1989a) The interaction of the upper airway and the thermometabolism on respiratory rhythm during non-rapid eye movement sleep in the developing lamb. J Dev Physiol 16, 37-43.

Andrews DC, Symonds ME \& Johnson PJ (1989b) Thermoregulation and the control of breathing during non-rapid eye movement sleep in the developing lamb. J Dev Physiol 16, 27-36.

Anflous K, Armstrong DD \& Craigen WJ (2001) Altered mitochondrial sensitivity for ADP and maintenance of creatine-stimulated respiration in oxidative striated muscle of VDAC1-deficient mice. J Biol Chem 276, 1954-1960.

Arsenijevic D, Onuma H, Pecqueur C, et al. (2000) Disruption of the uncoupling protein-2 gene in mice reveals a role in immunity and reactive oxygen species production. Nat Genet 26, 435-439.

Barker DJP, Godfrey KM, Fall C, Osmond C, Winter PD \& Shaheen SO (1991) Relation of birth weight and childhood respiratory infection to adult lung function and disease from obstructive airways disease. BMJ 303, 671-675.

Bauer MK, Breier BH, Harding J, Veldhuis JD \& Gluckman PD (1995) The fetal somatotrophic axis during long term maternal undernutrition in sheep; evidence of nutritional regulation in utero. Endocrinology 136, 1250-1257.

Budge H, Dandrea J, Mostyn A, et al. (2003) Differential effects of fetal number and maternal nutrition in late gestation on prolactin receptor abundance and adipose tissue development in the neonatal lamb. Pediatr Res 53, 302-308.

Buemann B, Schierning B, Toubro S, et al. (2001) The association between the val/ala-55 polymorphism of the uncoupling protein 2 gene and exercise efficiency. Int $J$ Obes Relat Metab Disord 25, 467-471.

Cassell PG, Neverova M, Janmohamed S, et al. (1999) An uncoupling protein 2 gene variant is associated with a raised body mass index but not Type II diabetes. Diabetologia 42, 688-692.

Clarke L, Heasman L, Firth K \& Symonds ME (1997) Influence of route of delivery and ambient temperature on thermoregulation in newborn lambs. Am J Physiol 272, R1931-R1939.

Clarke L, Heasman L, Juniper DT \& Symonds ME (1998) Maternal nutrition in early-mid gestation and placental size in sheep. Br J Nutr 79, 359-364.

Edwards LJ \& McMillen IC (2001) Maternal undernutrition increases arterial blood pressure in the sheep fetus during late gestation. $J$ Physiol 533, 561-570.

Edwards LJ, Symonds ME, Warnes K, et al. (2001) Responses of the fetal pituitary-adrenal axis to acute and chronic hypoglycaemia during late gestation in the sheep. Endocrinology 142, 1778-1785.

Fleury C, Neverova M, Collins S, et al. (1997) Uncoupling protein-2: a novel gene linked to obesity and hyperinsulinemia. Nat Genet 15, 269-272.

Fowden AL, Li J \& Forhead AJ (1998) Glucocorticoids and the preparation for life after birth: are there long-term consequences of the life insurance? Proc Nutr Soc 57, 113-122.

Gong DW, He Y, Karas M \& Reitman M (1997) Uncoupling protein-3 is a mediator of thermogenesis regulated by thyroid hormone, $\beta 3$-adrenergic agonists, and leptin. J Biol Chem 272, 24129-24132.

Lowry OH, Rosenbrough NJ, Farr AL \& Randall RJ (1951) Protein measurement with the Folin phenol reagent. $J$ Biol Chem 193, 265-275.

Mostyn A, Pearce S, Budge H, et al. (2003) Influence of cortisol on adipose tissue development in the fetal sheep during late gestation. $J$ Endocrinol 176, 23-30.

Negre-Salvayre A, Hirtz C, Carrera G, et al. (1997) A role for uncoupling protein-2 as a regulator of mitochondrial hydrogen peroxide generation. FASEB $J$ 11, 809-815.

Pecqueur C, Alves-Guerra M-C, Gelly C, et al. (2001) Uncoupling protein-2: in vivo distribution, induction upon oxidative stress and evidence for translational regulation. J Biol Chem 276, 8705-8712.

Ricquier D \& Bouillaud F (2000) The uncoupling protein homologues: UCP1, UCP2, UCP3, StUCP and AtUCP. Biochem J 345, 161-179.

Roseboom TJ, van der Meulen JHP, Osmond C, Barker DJP, Ravelli ACJ \& Blecker OP (2000) Plasma lipid profile in adults after perinatal exposure to famine. Am J Clin Nutr $\mathbf{7 2}$, $1101-1106$

Schermer SJ, Bird JA, Lomax MA, Shepherd DAL \& Symonds ME (1996) Effect of fetal thyroidectomy on brown adipose tissue and thermoregulation in newborn lambs. Reprod Fertil Dev 8, 995-1002.

Stuart JA, Harper JA, Brindle KM, Jekabsons MB \& Brand MD (2001) Physiological levels of mammalian uncoupling protein 2 do not uncouple yeast mitochondria. J Biol Chem 276, $18633-18639$.

Symonds ME, Andrews DC \& Johnson PJ (1989) The control of thermoregulation in the developing lamb during slow wave sleep. J Dev Physiol 11, 289-298.

Symonds ME, Bird JA, Clarke L, Gate JJ \& Lomax MA (1995) Nutrition, temperature and homeostasis during perinatal development. Exp Physiol 80, 907-940.

Symonds ME, Bryant MJ, Clarke L, Darby CJ \& Lomax MA (1992) Effect of maternal cold exposure on brown adipose tissue and thermogenesis in the neonatal lamb. J Physiol 455, 487-502.

Symonds ME, Lomax MA, Kenward MG, Andrews DC \& Johnson PJ (1993) Effect of the prenatal maternal environment on the control of breathing during non-rapid eye movement sleep in the developing lamb. J Dev Physiol 19, 43-50.

Voehringer DW, Hirschberg DL, Xiao J, et al. (2000) Gene microarray identification of redox and mitochondrial elements that control resistance or sensitivity to apoptosis. Proc Natl Acad Sci USA 97, 2680-2685.

Yuen BSJ, Owens PC, McFarlane J, et al. (2002) Circulating leptin concentrations are positively related to leptin mRNA expression in fetus adipose tissue in the pregnant ewe fed at or below maintenance energy requirements during late gestation. Biol Reprod 67, 911-916. 